\title{
OTC-27034-MS
}

\section{The Impact of Submarine Slides on Pipelines: Outcomes from the COFS-MERIWA JIP}

White D.J. (University of Western Australia, UWA), Randolph M.F. (UWA), Gaudin C. (UWA), Boylan N.P. (Norwegian Geotechnical Institute, formerly with UWA), Wang D. (UWA), Boukpeti N. (UWA), Zhu H. (Fugro Advanced Geomechanics, formerly with UWA) \& Sahdi F. (Universiti Malaysia Sarawak, formerly with UWA)

\author{
Copyright 2016, Offshore Technology Conference
}

This paper was prepared for presentation at the Offshore Technology Conference held in Houston, Texas, USA, 2-5 May 2016.

This paper was selected for presentation by an OTC program committee following review of information contained in an abstract submitted by the author(s). Contents of the paper have not been reviewed by the Offshore Technology Conference and are subject to correction by the author(s). The material does not necessarily reflect any position of the Offshore Technology Conference, its officers, or members. Electronic reproduction, distribution, or storage of any part of this paper without the written consent of the Offshore Technology Conference is prohibited. Permission to reproduce in print is restricted to an abstract of not more than 300 words; illustrations may not be copied. The abstract must contain conspicuous acknowledgment of OTC copyright.

\section{Abstract}

This paper presents key outcomes of a 3-year Joint Industry Project funded by 6 Operators on the impact of submarine slides on pipelines. This JIP developed new techniques to simulate slide runout, and assess the resulting loading and deformation of seabed pipelines. The work was distilled into guidance for practical application, which has found adoption on projects.

The JIP spanned (i) characterization of soils at the solid-fluid transition, (ii) computational modelling of slide runout - via depth-averaged and continuum finite element methods, (iii) physical and numerical modelling of slide runout and pipeline impact, and (iv) analytical studies of pipeline response during slide loading. These elements combine to provide an improved practical basis for quantifying the risk associated with slide-pipeline interaction.

To characterize very soft seabed soils, a new geotechnically-based framework was devised based on extensive measurements of different soils. This framework spans the solid-fluid boundary that is crossed as slides evolve into a debris flow and turbidity current. It is shown that the geotechnical link between water content and shear strength extends continuously - with no phase transformation - far into the fluid domain, allowing a single rheology to be applied throughout.

Computational modelling of slide runout used a hierarchy of methods, from large deformation finite element analysis (LDFE) (with rate effects and softening at soil element level), through depth-averaged runout, to energy-based analytical solutions. In some regimes of behavior the simpler methods suffice, allowing efficient use of Monte Carlo methods to tackle uncertainty. More complex runout modes can be replicated by newly-developed LDFE techniques.

From a runout analysis results, pipeline impact loads can be assessed using new solutions for the bearing capacity and drag forces on pipelines developed from numerical and physical modelling, which again unify concepts from fluid dynamics and geotechnics. Finally, simple analytical methods for assessing the structural response of a pipeline to a known slide loading are provided. These solutions allow rapid assessment of the response of a pipeline to a specified slide loading.

These advances improve the methods available for quantitative assessment of slide runout and slidepipeline interaction, allowing better determination of the resulting geohazard risk. 